\title{
Assessment of the Policy for Hospital Sector Partnership in Bulgaria
}

\author{
Chief. Assist. Prof. PhD Boncho Mitev \\ University of Economics - Varna, Varna, Bulgaria \\ bonchomitev@ue-varna.bg
}

\begin{abstract}
Successful partnerships in healthcare require government support by creating conditions that foster the relationships. The paper's aim is to analyze and evaluate the national policy for hospital sector partnership in Bulgaria. The study was conducted in two stages. First, a review of the political goals and priorities of various governments in the field of healthcare for the period 2001 - 2018 has been carried out on the basis of state documents, studies and political reports. Second, a survey on hospital managers' opinion for the state policy in hospital sector partnership has been conducted. The results show that there is a conviction among healthcare authorities in Bulgaria about the need of new organizational forms in the hospital sector in the context of the existing problems in it, but there is no consistent policy to implement them. The hospital managers should be involved in the process of partnership formation.
\end{abstract}

Keywords: partnership, policy, hospital, hospital managers, healthcare strategy.

JEL Code: I11, I18, M00; doi:10.36997/IJUSV-ESS/2019.8.1.84

\section{Въведение}

Динамичните изменения в съвремената бизнес среда, породени от нарастващата конкуренция, бурното технологично развитие и появата на нови потребности, индустрии и пазари, предопределят засиления интерес на организациите към колаборация. В основата на създаването на партньорски отношения лежи осъзнатата взаимна изгода, а разнообразните мотиви на участниците в тях произтичат най-общо от недостига на ресурси или от наличието на неоползотворени пазарни възможности (Mitev, 2016). Наред със синергичния ефект от сьтрудничеството се реализират редица ползи за партньорите, като намаляване на риска, икономии от мащаба, постигане на конкурентно предимство, гъвкавост и бърза реакция спрямо променящите се пазарни условия. Освен в областта на бизнеса, партньорства се развиват и в сферите от нестопанския сектор, като здравеопазване и образование, както и в държавното управление и отбраната под формата на политически или военни коалиции.

В здравеопазването, колаборацията се реализира в различни форми - обединения между конкуриращи се болници на местния пазар (Luke et al, 1995), договорни споразумения между лекари и болници (Murphy et al, 1994), мрежи, в които участват доставчици на медицински услуги и осигурители (Longest, 1990) и споразумения за аутсорсинг за определени дейности между болници и доставчици. Те се различават в зависимост от степента на интеграция между отделните участници, видовете партньори, техните цели и мотиви за сьтрудничество. Като цяло партньорските отношения в здравния сектор се развиват на базата на два модела: единият поставя в центъра пациента и цели осигуряване на неговото комплесно здравно обслужване, а другият акцентира върху ресурсите и тяхното по-икономично и ефикасно използване (Mutafova et al., 2005).

Освен ползите за пациента, произтичащи от предоставянето на интегрирани здравни грижи, колаборацията има редица положителни ефекти както за отделните участници, така и за здравната система като цяло. В условия на ресурсна ограниченост и силно конкурентен пазар, партньорството пидобива стратегическо значение за отделните лечебни заведения, защото чрез него едни от тях оцеляват, а други се развиват. На макрониво, тясното сътрудничество между лечебни и здравни заведения допринася за преодоляване на съществуващите дисбаланси в здравната система и води до повишаване на нейната ефективност. 
За реализиране на партньорства в силно регулирани пазари, какъвто е този в здравеопаването, е необходима целенасочена подкрепа от държавата чрез провеждане на последователна политика, стимулираща подобни връзки. През последните години, усилията на изпълнителната власт в България са насочени към създаване на подходяща среда за развиване на партньорства. Приети са редица стратегически документи в областта на здравеопазването, поставящи конкретни приоритети и цели за развитие, които са основа за формирането на здравната политика на страната. В някои от тях се обръща внимание върху развитието на различни форми на сътрудничество между болниците.

В тази връзка целта на настоящата статия е да се анализира и оцени политиката на здравните власти по отношение на създаването на партньорства в болничния сектор в България.

\section{1. Методи и материали}

За оценка на политиката по създаване на болнични партньортва у нас са използвани два ваимно допълващи се метода - здравно-политически анализ и изследване на ръководен болничен персонал. Проучването е проведено в два етапа.

Първо, извършен е преглед на политическите цели и приоритети на различни правителства в областта на здравеопазването за периода 2001 - 2018 г. на базата на държавни документи, изследвания и политически доклади. Целта е да се оцени политическата воля и предприетите стъпки за стимулиране развитието на партньорските отношения в болничния сектор. Акцентът е поставен върху идеята за колаборация, като се проследява еволюцията от нейното възникване до последващото ѝ проявление в различни организационни форми. Източниците включват публикувани стратегически документи (национални здравни стратегии и планове за действие за тяхното изпълнение), приети от Народното събрание, нормативни актове, проекти на стратегическа рамка на здравната политика, планове за болнично преструктуриране на Министерството на здравеопазването, както и доклади за реформата в здравния сектор, разработени от Световната банка.

Второ, проведено е проучване на мнението на болничните мениджъри относно провежданата политика на държавата в областта на създаването на партньорства в болничния сектор. Изследването е осьществено с помощта на полу-структурирана анкетна карта, съдържаща редица открити въпроси с възможност за извличане на личните мнения и схващания на респондентите. Включените въпроси касаят оценката на здравните мениджъри за политиката и основните виждания на управляващите за развитието на болничните заведения у нас. Интервюирани са ръководители на висше управленско ниво в болници на територията на България, които лично са попълнили анкетната карта с помощта на интервюиращ или чрез изпращане на въпросник по електронен път. Проучването е проведено през 2016 г. сред лечебни заведения за болнична помощ в рамките на представителна за страната извадка от 71 болници, различаващи се по функции, големина и форма на собственост.

\section{2. Резултати и дискусия}

\section{Здравно-политически анализ}

През последните години, усилията на изпълнителната власт са насочени към реформиране на здравната система за преустановяване на негативните тенденции в здравето на нацията, като се търсят начини за преодоляване на съществуващите дисбаланси в нея и подобряване на качеството на предоставяните здравни услуги. Приетите стратегически документи в областта на здравеопазването поставят конкретни приоритети и цели за развитие, които са основа за формирането на здравната политика на страната. В редица от тях се акцентира върху развитието на различни форми на сътрудничество между болниците. 
Пьрвият подобен документ е приетата през 2001 г. от правителството на Обединените демократични сили Национална здравна стратегия „По-добро здраве за по-добро бъдеще на България" за периода 2001 - 2010 г. Основните приоритети, които са заложени в нея, са свързани с подобряването на здравето на населението, структурни промени в здравната система с оглед повишаване на ефективността, развитие на пазарните отношения и конкуренцията, децентрализация и професионализиране на управлението, адаптиране на човешките ресурси към новите условия и професионални изисквания (Ministry of Health, 2001).

В документа са анализирани проблемите пред болничния сектор и се извежда необходимостта от преструктуриране на болниците, за да се отговори на обществените изисквания. Отбелязва се, че прилагането на нови организационни форми биха могли да решат тези проблеми, но е необходимо детайлно проучване на ролята и функциите им. Като подходяща форма са посочени болничните холдинги, които представляват големи лечебни заведения, осигуряващи интегрирано извънболнично и болнично лечение.

Опит за прилагане на подобна организационна форма на практика се реализира през 2003 г. със създаването на „Столичен медицински холдинг“ в София. В новата структура попадат 45 болници, диспансери и диагностично-консултативни центрове, като в повечето от тях холдингът държи $51 \%$ от акциите, а останалите $49 \%$ остават собственост на общината. Създаден по модела на здравните холдинги в Хамбург и Париж, идеята му е да улесни достьпа до здравна помощ и да се централизират обслужващите дейности (като хранене и транспорт). В действителност функционирането му е съпътствано от скандали, свързани с опасения за скрита приватизация на общинските болници в него. Наред с това са констатирани редица финансови злоупотреби, голяма част от лечебните заведения в холдинга трупат задължения и самият той в продължение на 3 години работи на загуба. Лошото управление и незадоволителните резултати водят до неговото ликвидиране през 2007 г. Липсата на действащи механизми за контрол на реализацията на подобно сътрудничество проваля последващи опити за създаване на успешни холдинги с участието на болници у нас.

През 2008 г. е приета нова Национална здравна стратегия 2008-2013 и План за действие за нейното изпълнение. В нея са засегнати основните предизвикателства пред здравната система. За болничния сектор се отбелязва наличието на съществени диспропорции по отношение на брой, географско разположение, характер на дейността, ресурсна обезпеченост на болниците. Посочват се проблемите с финансирането и издръжката на лечебните заведения като едни от основните за системата, които произтичат от големия брой болници, ниската използваемост на легловия фонд, неефективния мениджмънт и финансов контрол (Ministry of Health, 2008).

Някои от акцентите, които са поставени като приоритети, потвърждават заложените в предишната стратегия и са свързани с:

- подобряването на здравното състояние на населението;

- финансово стабилизиране на здравната система;

- развитие на човешките ресурси;

- подобряване на качеството, достьпа и ефективността на спешната и извънболничната помощ;

- преструктуриране, оптимизиране и ефективно управление на болничната помощ;

- създаване на интегрирана система за електронен обмен на данни в здравеопазването.

Една от заложените стратегически цели е свързана с преструктуриране и ефективно управление на болничната помощ. Посочва се, че преструктурирането на болничния сектор предполага ефективно разпределение на болничните структури според търсенето на пациентите, техните потребности, спецификата в демографската структура и 
заболеваемостта. Предвидени са конкретни задачи, сред които се планира въвеждане на публично-частно партньорство. В плана за действие е заложено изпълнението на тази задача до 2013 г. с отговорни институции - областните и общинските ръководства и източник на финансиране - бюджета на МЗ. Анализът на доклада по изпълнението на Националната здравна стратегия показва липсата на предприети действия за приемането на необходими нормативни актове и създаване на условия и механизми за реализиране на подобен род партньорство на практика в болничния сектор (Council of Ministers, 2013).

Цялостна визия за развитие на болничния сектор в България с поглед към разрешаване на натрупаните проблеми е представена в приетата през 2009 г. Концепция за преструктуриране на болничната помощ на Република България. Нейната главна цел е да се осигури равен и справедлив достьп на населението до всички видове болнична медицинска помощ, високо качество и ефективно разпределение на обществения ресурс на здравеопазването. Една от подцелите ѝ е мобилизиране на публично-частното партньорство за удовлетворяване на потребностите от болнична помощ на населението на територията на всеки административен район (Ministry of Health, 2009). Детайлният преглед на документа показва, че подобно на действащата стратегия, и тук липсват планирани конкретни мерки за стимулиране създаването на публично-частни партньорства.

В опит да обобщи приоритетите в приетите и допълващи се здравни стратегии и концепции за развитие на здравната система до момента, Министерството на здравеопазването разработва през 2012 г. Стратегическа рамка на политиката на здравеопазването за подобряване здравето на нацията в периода 2014 - 2020 г. Направеният анализ на демографското и здравното състояние на населението отчита трайна негативна тенденция на намаляването му в резултат на високата смъртност, ниската раждаемост и емиграцията, както и неговото застаряване. В документа са поставени пет национални цели на профилактика на заболяванията и подобряване на здравето на гражданите, чието реализиране да доведе до намаляване на смъртността с $20 \%$ в пет основни възрастови групи (Ministry of Health, 2012).

Във връзка с постигането на тези цели се предлагат няколко секторни политики в областта на първичната, болничната и спешната медицинска помощ, домовете за медикосоциални грижи и регионалната здравна политика. По отношение на болничния сектор се предвижда нов подход за оптимизиране на структурата, като акцентът се насочва от съкращаване на болнични легла към осигуряване на болнични услуги според потребностите на пациентите. Счита се, че най-голям ефект върху разходите на болничната система би се постигнал с преобразуването на цели, неефективни болници за активно лечение в лечебни заведения за продължително лечение, рехабилитация или други структури, предлагащи подходящи услуги. В тази връзка се посочва необходимостта от разработване и изпълнение на стратегия за управление на партньорството на болниците с лечебните заведения за извънболнична помощ, хосписите и социилните домове, но в крайна сметка подобен стратегически документ не е приет.

Възприетото като приоритет развитие на промотивно-профилактичните дейности у нас се потвърждава в следващата Национална здравна стратегия 2014 - 2020 г., приета през 2013 г. от правителството на Пламен Орешарски. Тя поставя пациента в центъра на здравната система и усилията се насочват към индивидуалния подход в неговото лечение. Залага се на къстомизацията ${ }^{1}$ на здравните услуги, развитието на транслационната и персонализираната медицина, интегриране на цялостното лечение и наблюдение на хронично болните, повишаване нивото на доверие и готовността на пациентите за лечение и др. (Ministry of Health, 2013).

За реализиране на приоритетите и целите на стратегията са разработени 11 политики с

${ }^{1}$ Определяне на лечението според индивидуалните биологични и личностни особености. 
конкретни мерки за провеждането им. Една от политиките е свързана с оптимизация на болничната помощ, чрез създаване на баланс между потребностите от хоспитализации, организацията на системата, количеството и качеството на ресурсите за тяхното задоволяване. Като подходяща мярка се посочва внедряването на модел на „болнични мрежи” от държавни и общински болнищи, който да бъде основа за преструктуриране на болничните легла. Подобно предложение прави Световната банка в свой доклад, в който посочва, че в отговор на огромните предизвикателства пред управлението на болничния сектор, би могла да се обмисли идеята за интегриране на държавните болници в конкуриращи се мрежи, в които да влизат лечебни заведения от различни нива (World Bank, 2013). Препоръчва се всяка мрежа да подписва един договор с НЗОК, което би създало силни стимули за оптимизиране предоставянето на услуги в рамките на мрежата. Освен това се посочва, че консолидирането на болнични услуги трябва да е съпътствано от изработването и изпълнението на междусекторна стратегия за продължителни медицински грижи. Като аргумент се изтъква фактът, че бързо застаряващото население на България има нужда от продължително лечение или дългосрочна грижа, което може да получи при по-високо качество и по-ниска цена в адаптирана за целта среда. Реални действия за създаване на условия за развитие на болнични мрежи обаче не са предприети.

На 17.12.2015 г. е приета актуализираната Национална здравна стратегия 2020 г. и План за действие за изпълнението й. При нейния преглед прави впечатление, че напълно е възприета препорьката на Световната банка за консолидация на болнични структури, за реализирането на която фрагментираната болнична мрежа създава добри условия. Ползите от едно такова решение са за двете страни - пациентът получава комплексно обслужване, а болниците ефективно използват своя капацитет. В стратегията се посочва, че към такива действия трябва да се пристьпи след влизането в сила на задължителна Национална здравна карта, чрез която за всяка област да бъдат планирани необходимите основни болнични дейности, съответстващи на потребностите на обслужваното население. Предвидени са конкретни мерки и дейности за внедряване на идеята за консолидация на болнични структури (Таблица 1).

Таблица 1. Политика 2.5. Оптимизирана болнична мрежа

\begin{tabular}{|c|c|c|}
\hline Мярка & Дейности по мярка & $\begin{array}{c}\text { Индикатори за } \\
\text { мониторинг }\end{array}$ \\
\hline \multirow{3}{*}{$\begin{array}{l}\text { Мярка 2.5.4. } \\
\text { Стимулиране } \\
\text { създаването на } \\
\text { болнични } \\
\text { обединения с цел } \\
\text { осигуряване на } \\
\text { комплексно } \\
\text { обслужване на } \\
\text { пациентите и } \\
\text { ефективно } \\
\text { използване на } \\
\text { болничните } \\
\text { ресурси. }\end{array}$} & $\begin{array}{l}\text { Дейност 2.5.4.1. Нормативно регламентиране на } \\
\text { възможностите за създаване на обединения на } \\
\text { изпьлнителите на медицински услуги за } \\
\text { сключване на договор с НЗОК. }\end{array}$ & $\begin{array}{l}\text { Приет пакет } \\
\text { нормативни актове }\end{array}$ \\
\hline & $\begin{array}{l}\text { Дейност 2.5.4.2. Въвеждане на изисквания за } \\
\text { осигуряване на комплексно обслужване на } \\
\text { пациентите за медицинските дейности, } \\
\text { финансирани с публични средства. }\end{array}$ & $\begin{array}{l}\text { Приет пакет } \\
\text { нормативни актове } \\
\text { Актуализирани } \\
\text { медицински } \\
\text { стандарти } \\
\end{array}$ \\
\hline & $\begin{array}{l}\text { Дейност 2.5.4.3. Осигуряване на възможност за } \\
\text { ползване на общ капацитет и отпадане на } \\
\text { задължителни дублиращи се структури в } \\
\text { рамките на обединението. }\end{array}$ & $\begin{array}{l}\text { Актуализирани } \\
\text { медицински } \\
\text { стандарти }\end{array}$ \\
\hline
\end{tabular}

Източник: План за действие за изпълнение на Националната здравна стратегия 2020.

По реализацията на мярка 2.5.4. са предприети конкретни действия, които създават предпоставки за стимулиране на болниците да търсят партньорства с други лечебни заведения или организации извън здравната система (Council of Ministers, 2017): 
- Приета е Националната здравна карта и започва прилагането на въведения механизъм за селективен подбор при сключване на договор от страна на НЗОК.

- Регламентира се пакет „комплексно лечение“, състоящ се от отделни клинични пътеки и процедури, свързани с цялостното лечение на определени групи заболявания. НЗОК следва да сключва договор за този пакет с изпълнители, които имат осигурени възможности - самостоятелно или чрез договори или обединения с други лечебни заведения - за всички дейности по пакета.

- Чрез промени в нормативната уредба са регламентирани условията и реда за предоставяне на дейности по комплексни медицински грижи за определени заболявания в болници за активно лечение. Тази нова дейност, която могат да извършват болниците, предполага развитие на партньорски отношения с организации, предоставящи социални услуги на населението.

Подобна консолидация на лечебни заведения вече се осъществява в България. През 2015 г. 9 бургаски болници подписват договор за учредяване на консорциум „Обединени бургаски болници”. Това е първият болничен консорциум у нас, в който влизат лечебни заведения с различна собственост, които запазват своята юридическа самостоятелност. Целта е да се намалят административните разходи и да се увеличи капацитета на включените в него болници, което ще подобри обслужването на пациентите. Все още не е отчетен реалният ефект от тази колаборация, както за самите лечебни заведения, така и за заинтересованите страни.

През 2015 г. М3 предприема действия за сливане на 9 университетски болници в София чрез създаване на гражданско дружество, което да обедини техните администрации и да отговаря за управлението на немедицинските им дейности. Аргументите за това решение са раздутата администрация на отделните болници, както и дублирането в извършването на медицински дейности, доставки, оборудване и поддръжка. Липсата на желание за сътрудничество от страна на ръководставата на държавните болници води до невъзможност за реализиране на партньорство между тях и две години по-късно обединението се разпуска.

Наличието на осъзната необходимост за консолидиране на болнични структури от страна на болничните ръководители е от критично значение за реализирането на успешни партньорства в сектора. Подобни добри примери са вливането на МБАЛ Нови Пазар в МБАЛ Шумен през 2016 година и създаването на МБАЛ „Югозападна болница“, обединяваща две съществуващи лечебни заведения през 2017 година. Причините за подобно решение се коренят в ресурсната ограниченост на партньорите и осигуряване на възможност за оцеляване.

Някои форми на сътрудничество между болниците и лечебни и здравни заведения, както и с други организации извън областта на здравеопазването, са регламентирани в здравното законодателство. Сьгласно разпоредбите на Закона за лечебните заведения е вменено задължението на болниците да си взаимодействат с други лечебни заведения с ресурсите, с които разполагат, при настъпване на извънредни обстоятелства (природни бедствия, епидемии и др.) независимо от формата им на собственост. В този случай инициатори за сьтрудничеството не са лечебните заведения, a то е породено от необходимостта от защита на населението и на обществения интерес. Освен това болниците могат да се договарят помежду си и с други лечебни заведения за предоставяне на медицински специалисти, медицински услуги и други дейности. По линия на частното здравно осигуряване е регламентирано правото им да сключват договори със застрахователи, лицензирани да предоставят здравни застраховки за заболяване на населението. Лечебните заведения могат да взаимодействат помежду си и със съсловни и пациентски организации с цел да създават и участват в системи за оценка на качеството на техните дейности. (Health Care Establishments Act, 1999). 
Въз основа на анализа на стратегическите документи и промените в нормативната уредба в областта на здравеопазването можем да направим следните изводи и обобщения:

- Налице е убеденост сред органите на управление на здравната система у нас относно необходимостта от прилагането на нови организационно-управленски форми в болничния сектор в контекста на съществуващите проблеми в него.

- В стратегическите документи присьства идеята за развиване на партньорски отношения между болниците, но липсват последователни политики по реализиране на конкретните им форми.

- След 2015 г. се наблюдава известна приемственост в здравната политика по отношение развитието на колаборацията между лечебните заведения чрез прилагане на последователни мерки.

\section{Оценка на държавната политика по отночение на партньорствата от страна на болничите ръководители}

Проучването на мнението на болничните мениджъри относно държавната здравна политика е част от по-мащабно изследване, имащо за цел да се анализира предишния опит на болничните ръководители при реализиране на партньорства, нагласите и мотивите им за сътрудничество с други лечебни и здравни заведения, както и с организации извън здравната система. За оценка на политиката по създаване на партньорства в болничния сектор са използвани предимно открити въпроси, които дават възможност за по-свободно интерпретиране и представяне на собствените схващания на респондентите.

Преобладаващо е мнението сред болничните ръководители, че с провежданата от държавата здравна политика не се стимулира партньорството между лечебните заведения (Фигура 1). Едва около $10 \%$ от респондентите считат, че държавата е създала необходимите условия за развитие на сътрудничеството в болничния сектор. Впечатление прави крайно негативното мнение на ръководителите на публични болници относно подкрепата на държавата в тази насока, докато 23,53\% от мениджърите на частните болници определят държавната политика като подкрепяща колаборацията между лечебните заведения. Възможно обяснение на този факт може да се търси в нагласата на частните болници да разчитат по-скоро на собствения си потенциал и по-малко на държавата.

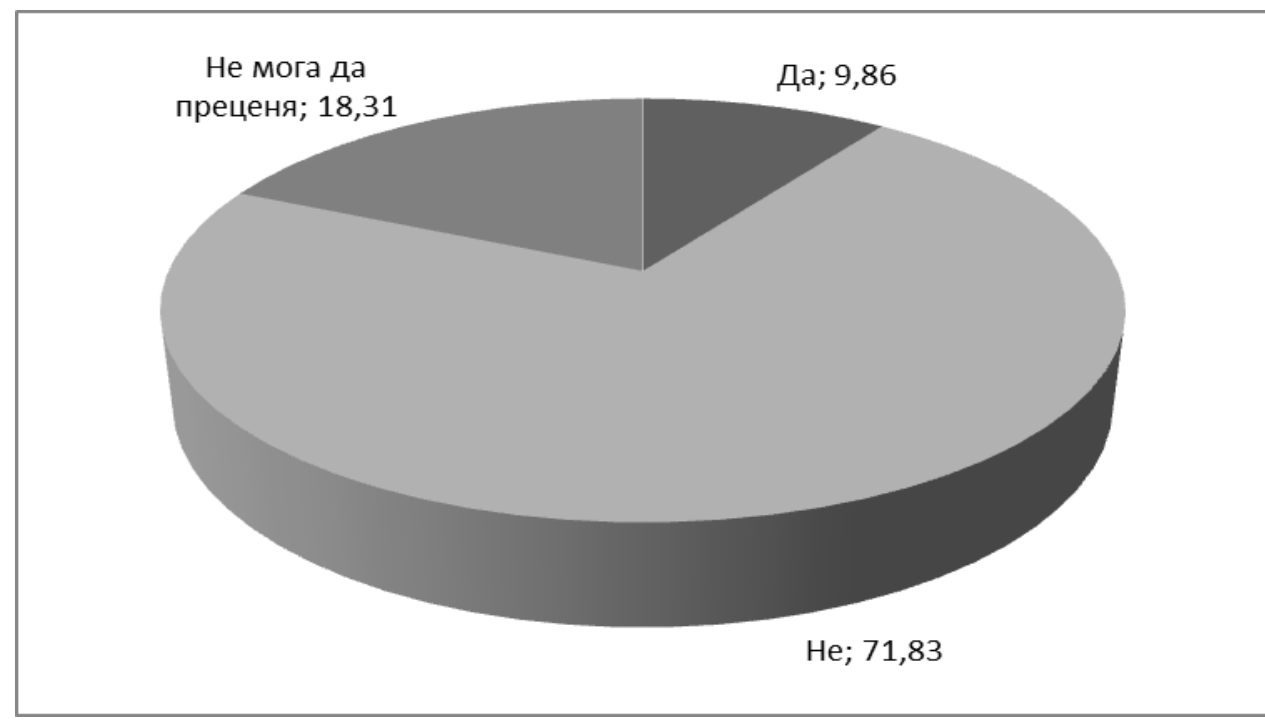

Фигура 1. Мнение на респондентите относно стимулиращата роля на държавата по отношение на партньорствата в болничния сектор.

Сред основните бариери пред реализирането на успешни партньорства в болничния сектор около 68\% от респондентите посочват нестабилната външна среда. От 
преобладаващите отговори на ръководителите на откритите въпроси става ясно, че те я асоциират с политиката на държавата. Те определят като пречки пред сьтрудничеството „липсата на последователна политика”, „липсата на ясна законова уредба, регламентираща тези отношения”, ,липсата на стабилна държавна политика в областта на здравеопазването”, „наличието на лобистка намеса в здравеопазването”, „липсата на дългосрочно отстоявана от държавата политика”, „абдикачия на държавата от ангажиментите си в здравеопазването". Тези негативни оценки потвърждават мнението на болничните мениджъри за непоследователната политика на държавата в областта на създаването на партньорства в здравеопазването.

Друга спирачка пред развитие на партньорските отношения болничните ръководители откриват в липсата на условия за осигуряване на равнопоставеност на участниците в колаборацията. В техните отговори- „борбата за пациенти, наложена от начина на разпределение на финансите от РЗОК”, "стремежа на някои болници да монополизират местния пазар","неравнопоставеността между болниците с различна собственост" прозират страховете за неравностойно положение на някои лечебни заведения в бъдещи партньорства. Липсата на добри практики у нас също се възприема като причина за недостатъчното развитие на кооперирането в болничния сектор.

Наред с външните фактори, болничните мениджъри посочват и някои вътрешни променливи, които затрудняват колаборацията между лечебните заведения - липсата на лоялност между партньорите, лошата координация в съвместната дейност и нежеланието на ръководителите да загубят управленската си автономност. В изследването обаче респондентите отбелязват водещата роля на държавата за стимулиране създаването на партньорства. Според тях „наличието на ясни пазарни отношения“, „създаването на законодателна уредба, касаеща тези взаимоотношения“, „осигуряване на равнопоставеност и ясни правила, валидни за всички болници“" са необходими мерки, които биха улеснили сътрудничеството между болниците.

През отделните етапи на здравната реформа у нас са обсъждани различни идеи за развитие на болничния сектор. За някои от тях са предприети конкретни мерки за реализиране, но не се осъществяват, а други си остават само като намерения. В таблица 2 е представена оценката на болничните мениджъри на някои от най-дискутираните насоки на здравната политика по отношение на болничния сектор през годините.

Таблица 2. Мнение на респондентите относно някои дискутирани насоки в здравната политика по отношение на болничния сектор (относителен дял на респондентите, в \%)

\begin{tabular}{|l|c|c|c|c|c|}
\hline \multicolumn{1}{|c|}{ Намерения } & $\begin{array}{c}\text { Напълно } \\
\text { сьгласен }\end{array}$ & $\begin{array}{c}\text { По-скоро } \\
\text { сьгласен }\end{array}$ & $\begin{array}{c}\text { Нито сьгласен, } \\
\text { нито несьгласен }\end{array}$ & $\begin{array}{c}\text { По-скоро } \\
\text { несьгласен }\end{array}$ & $\begin{array}{c}\text { Напълно } \\
\text { несьгласен }\end{array}$ \\
\hline $\begin{array}{l}\text { Приватизация на всички публични } \\
\text { болници }\end{array}$ & 39,44 & 30,99 & 8,45 & 16,90 & 4,23 \\
\hline $\begin{array}{l}\text { Приватизация само на отделни } \\
\text { публични болници }\end{array}$ & 9,86 & 26,76 & 8,45 & 49,30 & 5,63 \\
\hline $\begin{array}{l}\text { Отдаване на концесия на болници } \\
\text { за определен период от време }\end{array}$ & 18,31 & 23,94 & 30,99 & 26,76 & 0 \\
\hline $\begin{array}{l}\text { Отдаване на концесия на отделни } \\
\text { медицински дейности в болниците } \\
\text { за определен период от време }\end{array}$ & 4,23 & 42,25 & 8,45 & 40,85 & 4,23 \\
\hline $\begin{array}{l}\text { Преобразуване на публичните } \\
\text { болници в нестопански } \\
\text { организации }\end{array}$ & 32,39 & 28,17 & 30,99 & 8,45 & 0 \\
\hline $\begin{array}{l}\text { Развиване на публично-частното } \\
\text { партньорство в болничния сектор }\end{array}$ & 0 & 4,23 & 14,08 & 39,44 & 42,25 \\
\hline
\end{tabular}

Най-силна подкрепа сред респондентите получава идеята за приватизация на лечебните заведения. Те считат, че този процес трябва да обхваща всички публични болници, 
а да не се отнася само за определен кръг от лечебни заведения. Обяснение на тази позиция може да се търси в заплахата, която виждат болничните мениджъри да се придобиват само лечебни заведения с висок потенциал за развитие за сметка на малките общински болници, които не са привлекателни за частните инвеститори. От изразеното мнение на болничните ръководители е видно, че има съгласие по въпроса за промяна в статута на болниците от търговски дружества в нестопански организации. Тази идея е в унисон с изразяваната през годините критика на действащия пазарен механизъм в здравеопазването и търговския характер на лечебните заведения.

Проучването показва наличието на силно неодобрение от страна на болничните ръководители относно публично-частното партньорство като форма на колаборация в сектора. Причините вероятно се коренят в лошите примери на реализирани подобни партньорства в практиката, които са с компрометирани цели и резултати. Липсата на яснота и последователност в здравната политика пораждат неразбиране от страна на мениджърите за положителните ефекти от концесионирането на лечебни заведения за болнична помощ като форма за привличане на частни инвеститори.

\section{Заключение}

Анализът и оценката на политиката по създаване на партньорства в болничния сектор показват, че здравните власти у нас осъзнават необходимостта от въвеждане на нови организационни форми, но още липсва ясна визия относно конкретните им проявления и тяхното прилагане на практика. Успешното им реализиране изисква политическа воля и широка подкрепа за предприетите мерки, както и провеждане на последователна политика, която да съдейства за колаборацията между болниците. Последващите действията за осъществяване на мерките трябва да са свързани с анализ на ефектите от предприетите действия и разширяване на стимулите, механизмите и управленските решения за консолидиране на болничния сектор, без това да наруши достъпа на населението до необходимата медицинска помощ. От особена важност е в процеса на създаването и развитието на партньорски отношения между болниците да бъдат приобщени ръководителите на лечебните заведения. Здравните власти, чрез политиката, която провеждат, трябва да подпомагат мениджърите сами да осъзнаят необходимостта от сьтрудничество в сектора и да работят убедено и целеустремено за успешно партньорство.

\section{References}

1. Council of Ministers (2013) Annual Report on the State of Health of Citizens and the Implementation of the National Health Strategy in 2012. Available from: https://www.strategy.bg/FileHandler.ashx?fileId=4327 (in Bulgarian).

2. Council of Ministers (2017) Annual Report on the State of Health of Citizens and the Implementation of the National Health Strategy 2020 in 2016. Available from: https://www.strategy.bg/FileHandler.ashx?fileId=17044 (in Bulgarian).

3. Health Care Establishments Act. State Gazette No. 62, 9 July 1999; last amended 28 May 2019 (in Bulgarian).

4. Longest, B. (1990) Inter-Organizational Linkages in the Health Care Sector. Health Care Management Review. 15 (1). pp. 17-28.

5. Luke, R. and Olden, P. (1995) Foundations of Market Restructuring: Local hospital, Clusters and HMO Infiltration. Medical Interface. 8 (9). pp. 71-75.

6. Ministry of Health (2001) National Health Strategy "Better Health for Better Future for Bulgaria”. Sofia. (in Bulgarian). 
7. Ministry of Health (2008) National Health Strategy 2008 - 2013. Available from: https://www.strategy.bg/FileHandler.ashx?fileId=711 (in Bulgarian).

8. Ministry of Health (2009) Concept of Restructuring of Hospital Medical Care in Bulgaria. Sofia. Available from: https://www.strategy.bg/FileHandler.ashx?fileId=1027 (in Bulgarian).

9. Ministry of Health (2012) Draft Health Policy Strategic Framework for Improving the Health of the Nation 2014-2020. Sofia. (in Bulgarian).

10. Ministry of Health (2013) National Health Strategy 2014 - 2020. Sofia. (in Bulgarian).

11. Mitev, B. (2016) Essential Characteristics of Strategic Alliances. Izvestia Journal of the Union of Scientists - Varna, Economic Science Series. 1. pp. 109-115.

12. Murphy, T. M. and Harding, C. (1994) Hospital-Physician Integration: Strategies for Success. AHA Publ.

13. Mutafova, E., Atanasova, E., Dimitrova, L., Sherbetova, E., Feodorova, E., Racheva, M. (2005) Healthcare Management. Planning and Financing in the Hospitals. Sofia. (in Bulgarian).

14. World Bank (2013) Healthcare Reforms Policy Notes. Bulgaria, 2012. Washington. (in Bulgarian). 